\title{
AMADOR DE LOS RÍOS
}

DAVID ROMANO

Universidad de Barcelona

\section{INTRODUCCIÓN *}

En el curso de mis amplias lecturas e investigaciones sobre la historia de los hispanojudíos, con muchísima frecuencia he encontrado citas y referencias a la pionera (1875-1876) Historia social, política y religiosa de los judios de España y Portugal ', desarrollo de uno de los tres ensayos (1848) que forman los Estudios históricos, políticos y literarios sobre los judios de España ${ }^{2}$, que, a su vez, seguían varios artículos publicados en la Revista del Español (Madrid 1845-1846).

Pero en cuanto al apellido de su autor, entre los eruditos españoles de hoy coexisten dos corrientes: para unos se trata de Amador de los Ríos (José) mientras que otros le llaman Ríos (José Amador de los), corrientes originadas, entre otras razones, por el hecho de que Amador también puede ser nombre de pila.

Para mí, lo más curioso - acaso fue también lo... decisivo para

* En la realización de este trabajo me he beneficiado parcialmente de la ayuda del proyecto $n^{\circ}$ PB90-0449-C02-01 de la Dirección General de Investigación Científica y Técnica (DGICYT) del Ministerio de Educación y Ciencia. Agradezco muchísimo a mi fraternal amigo Juan Vernet por haberme procurado fotocopias de los documentos que figuran en el expediente de la Real Academia de la Historia.

$1 \mathrm{~J}$. AMADOR DE LOS Ríos, Historia social, politica y religiosa de los judios de España y Portugal. Madrid 1875-1876. 3 vols. Omito la referencia completa de las reimpresiones y reediciones; tan sólo mencionaré la reedición, parcial, de la editorial barcelonesa Orbis (Historia social politica y religiosa de los judios en España, Barcelona 1986), que antepone una breve biografia introductoria de Jordi Bafieres.

2 J. AMADOR DE los Rios, Estudios históricos, politicos y literarios sobre los judios de España, Madrid 1848. Recordaré que existe una versión francesa de J. G. Magnabal, Paris 1861. 
mi decisión- es que un erudito inglés, Joseph Jacobs ${ }^{3}$, alfabetizara el apellido por la letra A y no por la $\mathrm{R}$, pese a la tendencia inglesa ( $y$, en general, europea allende el Pirineo) de considerar que los nombres de persona constan de un first name -es algo así como un prenombre- y un last name - sería el apellido-, entre los cuales puede haber intermediate names, sin parar mientes en la ley española de los dos apellidos, paterno y materno, que legalmente debieran ir enlazados por la conjunción copulativa "y", lo que resulta necesario/oportuno en aquellos casos en que uno de esos dos apellidos también puede ser prenombre. El ejemplo más evidente parece ser el de Ramón y Cajal, que casi siempre se escribe con la "y" (excepto los ingleses que suelen llamarle simplemente Cajal).

Pero ante la insistencia/divergencia de tantos historiadores sobre este punto aparentemente anodino ${ }^{4}$, me creí obligado a iniciar la búsqueda de una solución razonada, cuyos resultados resumo aquí de una manera ordenada, que no es precisamente el orden fortuito en que los fui hallando. En esta exposición prescindo de los pasos que parecen, me parecen, accesorios.

\section{LOS ERUDITOS DEL SIGLO XIX}

La erudición decimonónica suele inclinarse por considerar que el primer apellido es Ríos: en este sentido, recordaré aquí el Diccionario enciclopédico publicado en las últimas décadas del siglo ${ }^{5}$.

En la necrología inserta en el Boletín de la Real Academia de la Historia ${ }^{6}$ en dos ocasiones se le llama Sr. Ríos.

El biógrafo Francisco Valverde - la obra a la que me refiero fue publicada aprincipios del siglo $\mathrm{XX}$ - señala que era hijo de José de

${ }^{3}$ J. JACOBS, An inquiry into the sources of the History of the Jews in Spain, London 1894, págs. 214-221. Véase D. Romano, “Análisis de los repertorios documentales de Jacobs y Régné», Sefarad XIV (1954) 247-264. Reimpresión en D. Romano, De historia judía hispánica, Barcelona 1991, 25-42.

${ }^{4}$ Entre los muchos escritos más o menos biográficos que no aclaran la cuestión pero citan a nuestro autor por la palabra Amador, mencionaré aquí las biografías de Valverde (véase mi nota 7) y de Bañeres (véase mi nota 1).

5 Diccionario enciclopédico hispanoamericano de literatura, ciencias y artes Barcelona 1887-1910, vol. II (1887) pág. 8, col. 1, remite a Ríos: vol. XVII (1895) págs. 695-696. Agradezco la indicación a Juan Vernet.

${ }^{6}$ BRAH I (1877-1879) 105-109. 
los Ríos (y de María del Carmen Serrano) ${ }^{7}$, aunque al hablar de nuestro personaje en todos los casos le menciona como Amador (o Amador de los Ríos). Por otra parte, es más que oportuno recordar que Fernández y González, que reunía la condición de ser yerno de don José, siempre le menciona como Amador ${ }^{8}$.

Buscando fuentes más objetivas, siempre coetáneas, del siglo XIX, no he sabido encontrar solución en los escalafones de catedráticos universitarios ${ }^{9}$, ni en listas de académicos de la Real Academia de la Historia ni tampoco de la Real Academia de San Fernando, a la que pertenecieron tanto D. José como su hijo D. Rodrigo. Sin embargo, en el Indice de sesiones del Congreso de Diputados de 1863-1864, es decir, anterior a la institución del Registro Civil, se le cita como "AMADOR DE LOS RIOS (Sr. D. José)» ${ }^{10}$. En una carta dirigida por su hijo Rodrigo al Secretario de la Real Academia de la Historia alguien escribió un epígrafe «Amador de los Ríos José (De $\left.\mathrm{n}^{\mathrm{Q}}\right) \gg "$ ".

Recordaré, además, que el erudito inglés Jacobs lo alfabetiza por Amador. Es decir, que algunos testimonios decimonónicos consideran que el primer apellido es Ríos, y otros - curiosamente uno de ellos es Fernández y González, el yerno de nuestro autor- lo citan como Amador.

La esquela - no me consta dónde se publicó (seguramente en Sevilla) - conservada en el expediente de la Real Academia de la Historia no ayuda a resolver la cuestión: su nombre figura como José Amador de los Ríos y Padilla, sin que nada destaque el apellido.

${ }^{7}$ F. Valverde y Perales, Historia de la villa de Baena (Toledo 1903), pág. 418. En la pág. 433 cita una lápida que se colocó en su casa natal, en la que el nombre de nuestro personaje es José Amador de los Ríos y Serrano. Y me pregunto: ¿por qué la esquela mortuoria, a la que me referiré al final de este párrafo, lleva el nombre de José Amador de los Ríos y Padilla?

${ }^{8}$ F. FERnÁndez y GonZÁlez, Instituciones jurídicas del Pueblo de Israel en los diferentes estados de la Península Ibérica desde su dispersión en tiempos del Emperador Adriano hasta los principios del siglo XVI, Madrid 1881, págs. 39, n. 3; 40, n. 2; 45, n. 3 ; etc.

9 Amador de los Ríos fue nombrado catedrático el 7.7.1948; cf. F. VALVERDE $Y$ Perales, Historia, pág. 424.

10 Indice del diario de las sesiones. Congreso de los Diputados. Esta legislatura dió principio en 4 de noviembre de 1863, y terminó en 23 de junio de 1864, Madrid, pág. 12. Las fotocopias de este índice me han sido proporcionadas por el Prof. Dr. Ernest Lluch.

"La carta se conserva en el expediente de la Real Academia de la Historia. 
2. LOS ERUDITOS DEL SIGLO XX

Si pasamos a nuestro siglo, quizás sea útil/significativo exponer la situación que ofrece la Enciclopedia Universal Ilustrada EuropeoAmericana (vulgo, "Espasa»). En la voz "Amador» 12 se recogen dos entradas:

Amador de los Ríos (José). Véase Ríos (Amador de los);

Amador de los Ríos y Villalta. Véase Ríos y Villalta (Amador de los),

es decir, que una y otra remiten a Ríos, de lo cual yo me atrevo a inferir que la cuestión era discutida/discutible en aquel entonces, "entonces" que yo creo que debe fijarse en un momento ligeramente anterior a 1914 '.

La lectura de los dos artículos, en la letra $\mathrm{R}^{14}$, aparte de otras informaciones que ahora no son pertinentes, revela esto:

Ríos (José Amador de los) Baena 1818 - Sevilla 1878;

Ríos y Fernández de Villalta (Rodrigo Amador de los) Madrid 1843-1917,

o sea, D. José aparentemente sin segundo apellido ${ }^{15}$, mientras que D. Rodrigo lleva el de Fernández de Villalta.

Me pregunto: ¿qué pasó? ¿Acaso los apellidos de D. José eran, por este orden, "Amador" y "de los Ríos" y, en cierto momento, que debiera determinarse, se arregló su apellido, que pasó a ser «de los Ríos»? ${ }^{16}$.

Ahora bien. Conviene recordar que muchos impresos hablan de él como Amador de los Ríos, sin anteponer ningún nombre de pila.

\section{HACIA UNA SOLUCIÓN DEL PROBLEMA}

En resumen, pese a ligeras vacilaciones, pensé que pudiera ser que a partir de un momento dado - ¿acaso fue después de la

12 “Espasa», vol. 5, pág. 10.

${ }^{13}$ En la edición que manejo, el volumen 5 del «Espasa" no lleva fecha ni colofón, ni tampoco los tienen los volúmenes 4 y 6 , en los que figuran las voces Alemania y Austria, que contienen los uniformes militares anteriores a la Primera Guerra Mundial.

14 “Espasa”, vol. 51, págs. 750-751 y 754.

${ }^{15}$ He aludido antes (véase mi nota 7) al "segundo" apellido de nuestro personaje.

16 Por la $\mathrm{R}$, aunque recientemente se tiende a alfabetizar por la palabra DE (¿será otra de las ecolalias generadas por la Comunidad Europea?). 
creación del Registro Civil, es decir, después del año 1870?- el originario Amador fuera postergado en favor de Ríos.

¿No nos hallaríamos ante un caso semejante al de Menéndez Pidal, que conocemos sin lugar a dudas, pues lo hemos vivido? Menéndez, primer apellido; Pidal, segundo apellido. Pero sus hijos llevan como primer apellido Menéndez Pidal; como segundo, el de la madre, Goyri.

En esta encrucijada di a leer la redacción provisional de esta nota a mi amigo el prof. José Manuel Blecua y Teijeiro. Me explicó que, en 1923, al hacer el examen de ingreso para bachillerato en el Instituto de Zaragoza, le examinó el catedrático ${ }^{17}$ de geografía e historia Juan Francisco Fernández y Amador de los Ríos, nieto de don José. Hechas las oportunas gestiones, mi buena amiga Asunción Blasco, historiadora de los hispanojudíos, logró que yo dispusiera ${ }^{18}$ de la fotocopia de la hoja de servicios así como del acta de nacimiento que figuran en el expediente de dicho catedrático: la partida de nacimiento está transcrita en el apéndice de este artículo (la hoja de servicios no aporta datos para el tema que me ocupa).

Frente a la información de este documento, debo señalar lo que dice el anuario de 1992 de la Real Academia de la Historia: en el índice onomástico la entrada "Amador de los Ríos" remite a «Ríos y Padilla»; la entrada "Ríos y Padilla» remite a la página 172, donde figura el siguiente texto (que acaba en la pág. 173):

D. José Amador DE LOS Ríos Y PADILLA

Tomó posesión el 18 de febrero de 1848 . $†$ el 17 de febrero de 1878.

Para nada ayuda la noticia de la pág. 197 de dicho anuario que indica que era:

Catedrático de "Historia Crítica de la Literatura Española», en la U. de Madrid; Director del Museo Arqueológico Nacional; Inspector de Instrucción Pública; Decano de la Facultad de Filosofía y Letras. De la R.A. de San Fernando (Medalla 16. ${ }^{2}{ }^{19}$.

${ }^{17}$ Como curiosidad indicaré que había sido catedrático en Barcelona.

${ }^{18}$ Se puso en contacto con el Dr. Luis González Antón: la mujer de éste, D. ${ }^{a}$ M. 'osé Casadevante, que trabaja en el Instituto Goya, de Zaragoza, consiguió fotocopias de los documentos que citaré en seguida.

${ }^{19}$ Es curioso que esta relación no diga que había sido vicerrector (1867) y rector (1868), pero sí que hubiera sido decano. Tampoco se señala, pero la omisión es más explicable, que hubiera sido diputado. 
En otras palabras, la entrada principal es por la $R$, mientras que la registrada por la A es secundaria.

Sin embargo, en la nota necrológica publicada tres lustros antes en el Boletín de la Institución, en dos ocasiones se le menciona como Amador de los Ríos ${ }^{20}$.

\section{SUGERENCIAS}

La confirmación definitiva de mi "hipótesis" podría venir de otra fuente. Quizás fuera útil buscar en la documentación coetánea las actas de fallecimiento de nuestros dos personajes, pues ambos murieron después de haber sido instituido el registro civil — cuando nacieron aún no existía-, respectivamente en Sevilla (1878) y Madrid (1917). Asimismo, quizás convendría buscar las inscripciones de bautismo en los registros parroquiales de Baena (parroquia de Santa María la Mayor, de 1818) y de Madrid (¿qué parroquia? 1843).

\section{RESUMEN CONCLUSIVO}

Intento establecer cuál era el verdadero apellido del historiador de los hispanojudíos, pues los eruditos actuales discrepan al llamarle unos Amador de los Ríos (José) y otros -entre ellos la Real Academia de la Historia- Ríos (José Amador de los).

En espera de que sea hallada y publicada la partida de bautismo y/o la de defunción, a partir del análisis de varios testimonios (de los siglos XIX y XX), y de una copia del acta de nacimiento de un nieto suyo, me parece indiscutible que el apellido de nuestro personaje debe alfabetizarse por Amador ${ }^{21}$.

\footnotetext{
${ }^{20}$ Marqués de Siete Iglesias, "Real Academia de la Historia. Catálogo de sus individuos. Noticias históricas sacadas de su archivo", BRAH CLXXV (1978) 347-349.

${ }^{21}$ Como nota curiosa diré que durante mi investigación hallé que el 12.6.1847 fue designado académico correspondiente de la Real Academia de Buenas Letras de Barcelona.
} 


\section{APÉNDICE}

Acta de nacimiento de Juan Francisco Fernández y Amador

Don Francisco Cebrian Fernandez de Villegas, Catedrático y Secretario del Instituto Nacional de Segunda Enseñanza de Zaragoza.

CERTIFICO: Qué D. Juan Francisco Fernandez y Amador me ha entregado una certificación de nacimiento que copiada a la letra dice: = Hay una poliza de duodecima clase de una pesetas. - y un sello de veinte céntimos.- Hay un sello en tinta del Juzgado municipal del Distrito de BUENAVISTA, Madrid.- Don Segundo Isaac de las Pozas y Langre, Juez Municipal suplente del Distrito de Buenavista de esta Corte.- Certifico que al folio doscientos treinta y dos vuelto del libro trece de nacimientos de este Registro Civil se halla el acta siguiente: = Número 1019 Juan Francisco Fernandez y Amador.- Al centro en la Villa de Madrid á las tres y media de la tarde del dia seis de Diciembre de mil ochocientos setenta y cuatro: el Señor Don Luis Gomez Acebo Juez Municipal del Distrito de Buenavista de la misma y Don Limo Villamelia Secretario en virtud de certificación del Médico forense de este Juzgado se constituyeron en la casa número dos cuarto principal derecha de la calle de Gongora y estando en ella compareció don Francisco Fernandez Gonzalez natural de la ciudad de Albacete, mayor de edad, casado, Abogado, Catedrático y Academico de la Historia, domiciliado en la misma casa presentando con objeto de que se incriba en el Registro Civil un niño y al efecto como padre del mismo declaró = Qué dicho niño nacio en la casa del declarante á las diez y media de la mañana del dia cuatro de los corrientes. = Qué es hijo legitimo del declarante y de su mujer $\mathrm{D}^{\mathrm{a}}$ Isabel Amador de los Rios y Fernandez de Villalta natural de la ciudad de Sevilla, mayor de edad, domiciliada en el de su marido. = Qué es nieto por linea paterna de Don Juan Fernandez y Rodriguez natural de Villatresmil provincia de Oviedo difunto y de Doña Dolores Gonzalez y Ortiz, natural de la ciudad de Granada, domiciliada en esta villa y por la materna de Don José Amador de los Rios natural de Baena provincia de Córdoba y de Doña Maria Juana Fernandez de Villalta natural de dicho Sevilla, domiciliados en esta Capital $=Y$ que al referido niño se le habian de poner los nombres de Juan Francisco, Miguel, Hamberto. $=$ Fueron testigos presenciales Don Salvador Marco y Coll natural de la Ciudad de Leon digo de Valencia mayor de edad, soltero, empleado, domiciliado en la calle del Gobernador número ocho y $\mathrm{D}$. Francisco de Leon casado, natural de Ubeda 
provincia de Jaen, mayor de edad, casado, empleado, domiciliado en la calle de Jardines número cuatro. = Leida integralmente á la acta é instadas las personas que deben suscribirla á que la leyeran por si mismas no habiendolo hecho se estampo en ella el sello del Juzgado Municipal y la firmaron el Señor Juez el declarante y los testigos y de todo ello certifico. = Hay un sello = Luis Gomez Acebo $=$ Francisco Fernandez Gonzalez $=$ Francisco de Leon $=$ Salvador Marco $=$ Lino Villamelia. - Concuerda con su original á que me remito. - Y para que conste expido la presente en Madrid á siete de Noviembre de mil ochocientos noventa y nueve.- Isaac de las Pozas y Langre.- Rubricado.- Firma ilegible.- Rubricado.Hay un sello en tinta. Juzgado Municipal del distrito de Buenavista de Madrid.-

Es copia fiel y exacta del original á que me refiero y para que conste firmo la presente con el visto Bueno del Muy Ilustre Sr. Director, en Zaragoza a veintiocho de Mayo de mil novecientos veintiseis.

$\mathrm{V}^{0} \mathrm{~B}^{\mathrm{o}}$

EL DIRECTOR

[hay una firma]

[hay un sello del Instituto]

Zaragoza, Instituto Goya, expedientes de profesores.

\section{RESUMEN}

Se trata de clarificar cuál es el verdadero apellido de D. José Amador de los Ríos; la confusión que hoy existe viene provocada por las diversas formas en que se menciona a este escritor en los documentos de su época. Se considera como hipótesis más fiable que Amador sea apellido y no nombre de pila.

\section{SUMMARY}

The author tries to clarify which is the actual surname of D. José Amador de los Ríos; a confusion has been generated by the diversity in the ways this writer has been mentioned in the documents of his times. In this article the author considers that Amador is a family name, not a Christian name, as a more reliable hypothesis. 